\title{
Improved Organizational Design of the Diagnostic and Therapeutic Process in Ovarian and Lung Cancer
}

\author{
Ewa Okoń-Horodyńska ${ }^{1} \mathbb{D D}^{\mathrm{a}}$, Tomasz Sierotowicz ${ }^{1} \mathbb{D}^{\mathrm{b}}$ and Agnieszka Sznyk ${ }^{2}$ \\ ${ }^{1}$ Jagiellonian University, Faculty of Management and Social Communication, \\ Institute of Economics, Finance and Management, Department of Economics and Innovation, \\ Prof. Lojasiewicza 4, 30-348, Krakow, Poland \\ ${ }_{2}^{2}$ Institute of Innovation and Responsible Development, INNOWO, Warsaw, Poland
}

\begin{abstract}
Keywords: Health Care and Well-being, Improvement of Diagnostic Process, Modeling and Simulation of Diagnostic Processes, Use ICT in Improved Diagnostic Process.

Abstract: $\quad$ A disease in each single patient can be one of a kind and an individual approach is needed. Tumors are in this case particularly risky. The main research problem, as a case study, was to demonstrate the length and composition of the current Polish diagnostic process for two most risky conditions: ovarian carcinoma and lung cancer, as well as to determine the causes for this. The main goal was to create a new, innovative model for time-improved diagnostic processes of ovarian and lung cancer. In order to achieve aims of this research, the BPMN and CPM were used. The main result of this study is a model of treatment processes in the indicated cases with organizational changes, encompassing all possible types of contact between the patient and the healthcare system. The entire diagnostic time for lung and ovarian cancer was shortened about $50 \%$, which significantly increases the chances of quick diagnosis and effective treatment. The newly designed and presented in the text model is an example of organizational innovation where implementation of ICT solutions, allows to achieve and even improve an optimal path leading to the development of personalized medicine.
\end{abstract}

\section{INTRODUCTION}

A disease in each single patient can be one of a kind and an individual approach is therefore needed. The proper treatment is undertaken with considerable delay. This delay can be divided into three types. The first concerns delay in diagnosis caused by too late first visit at the primary care physician (PCP) or insufficient knowledge of the PCP to notice certain symptoms. The second group of delay results from lengthy and rigid workup procedures (overlapping delay loop) and introduction of appropriate treatment due to accurate decisions. Finally, the third type of delay is associated with the reaction of the organism to therapy. The economic dimension of these types of delay and barriers in treatment cannot be left unnoticed. Damage to health caused by neoplasms renders the vast human potential, mainly the professional one, unexploited, and the costs of treatment and care over patients leave a mark in economies, which might threaten the future stability of public finances and cause a decrease in Gross National Product (GNP), not only in Poland. According to the Polish National Cancer Registry (Didkowska et al., 2015), there were 156.5 thousand new cases of malignancies and 94 thousand deaths due to such diseases in 2013. The incidence had increased by approximately 4 thousand. Malignant tumors constitute the second cause of mortality in Poland. In 2013, these diseases accounted for $26 \%$ of deaths among males and almost $23 \%$ among females. Malignant tumors are the principal cause of premature death (before the age of 65). This phenomenon is particularly evident in the female population: $33 \%$ of death in the group of young women and nearly $49 \%$ among middle-aged ones (Didkowska et al., 2015). In Poland, lung cancer (ICD10: C34) accounts for $1 / 3$ of all deaths due to malignant cancers among males and $15 \%$ among females. Ovarian carcinoma (ICD10: C56), in turn, is a cause of $6.2 \%$ of all deaths due to malignant cancers among Polish women. In

a(i) https://orcid.org/0000-0002-2548-254X

b(iD https://orcid.org/0000-0002-1462-8267 
2000-2002, one-year survival rates reached $71.9 \%$. This value remained similar in 2003-2005 (70.8\%) as though global innovations could not reach Poland. According to the EUROCARE-5 study (Eurocare, 2014), Poland, with 5-year survival among ovarian cancer patients of $34.5 \%$, falls below the European value, i.e. $37.6 \%$. Is this not the highest time for the implementation of personalized model of treatment in these cases? However, in order to do this properly and effectively, it is necessary to first review the existing process paths in the diagnosis and treatment of these diseases. The critical point in the treatment of these diseases is the moment of initiation of proper inpatient treatment as well as selection and application of individualized therapies. In order to perfect the entire process, one must first improve the diagnostic process because the moment of initiation and duration of proper treatment depends upon the efficiency and efficacy of diagnosis. This paper, describes a design of a processes, starting with the first contact up to the conclusion of personalized therapy and a return to social and economic functioning. The process includes the main scheme up to a detailed and complex hospital treatment. The main research problem was to demonstrate the length and composition of the current Polish diagnostic process for two most risky conditions, i.e. ovarian carcinoma and lung cancer, as well as to determine the causes for this. The results of this application study are models of the treatment process in the indicated cases with organizational changes, encompassing all possible types of contact between the patient and the healthcare system. These models are a pilot undertaking that ought to be popularized if the results described in the conclusions, which depict an optimal development path for Polish personalized medicine, are desired.

\section{LITERATURE REVIEW}

An optimal diagnostic process, i.e. a process which is as short as possible and leads to establishing an accurate diagnosis, is an important factor, not only for the time of recovery and re-initiation of professional activity, which lowers losses for the economy, but also for the efficacy of subsequent treatment (Rivera et al., 2013). Diagnosis, proper inpatient treatment and individualized post-hospital therapy are subprocesses that comprise one diagnostic and therapeutic process of a given disease, occurring in certain specified conditions of the healthcare system in a given country. The diversification of processes in terms of their duration results from both the type of disease and its stage of progression. That is why optimization must be conducted for a given process that encompasses the subprocesses of diagnosis and treatment proper for a given disease. Diseases that pose the greatest challenge in establishing a rapid diagnosis include ovarian carcinoma and lung cancer. In these cases, improvement of time needed to make a diagnosis seems to be of fundamental significance due to the fact that initial symptoms are not necessarily specific, and the efficacy of the proper treatment strongly depends on the time of its initiation (Havrileskya et al., 2009). The issue of optimizing the diagnostic process in ovarian and lung cancers is not new (Evans et al., 2007; Collins et al., 2007). Good practice concerning optimal organization of the diagnostic process in terms of its duration and establishing an accurate diagnosis vary depending on a country. This results from the diversity of healthcare systems. They can be helpful in identifying the major barriers on the way to proper diagnosis and treatment. Obviously, they cannot eliminate all barriers and are not ready instruments for optimal solutions in other healthcare systems (Evans et. al., 2007).

\section{MATERIALS AND METHODS}

In real environments, it is common to deal with process characterized by incremental development, followed by agile approaches and time improved methods such as Critical Path Method (CPM). For this reason, the processes under research have to be considered to be continuous (Kunze et al., 2016). This iterative approach to the process re-thinking along with organizational change of both the structure and the outcomes of a process is often referred to as process re-engineering. In the presented solution, the process will be change in order to time-improvement all steps of diagnostic part of process. As a result, the treatment can be start at earliest opportunity with using the same medical assets.

\subsection{Conceptual Framework and Assumptions}

Improvement of the diagnostic and therapeutic process requires an individual approach to the process that consists of various consecutive events. This study is an attempt to identify and design organizational changes aiming at shortening the duration of diagnosing ovarian and lung cancers using existing material and non-material resources, on the basis of the optimization of current treatment processes of these diseases. Therapy in ovarian and lung cancers consists of three subprocesses: diagnosis, hospital treatment 
and individual post-hospital therapy. Since the main aim of the study is to optimize the duration of the diagnostic subprocess, it was necessary to obtain detailed data concerning this subprocess, which is a part of the patient treatment process.

\subsection{Data}

In the Polish healthcare system, the therapeutic process is different for each patient (which considerably prolongs the diagnostic process and treatment proper) instead of creating certain specific disease-and patient-based groups. Thus, data collected for the study were collected from two sources: the Polish healthcare system and patients participating in the therapeutic process for ovarian and lung cancers. These data allow to identify all possible events that could occur depending on: the type of physician whom patients consult initially, symptoms that are identified and the number of specialists that can take part in the diagnostic process. At the same time, the minimum and maximum time periods associated with awaiting individual actions were distinguished.

\subsection{Methods}

Management sciences currently have at their disposal computer tools for process management. These make use of standards enabling description of various processes characterized by variable complexity (Ouyang et al., 2008; Grosskopf et al., 2009). The application of these tools is not limited to business processes only. In particular, the Business Process Management Notation (BPMN) standard can be used for description, simulation and optimization of diagnostic and therapeutic processes (Allweyer, 2008; White, Bock, 2011). Process optimization and its associated modification not only allow to identify bottlenecks, but allows the entire process to be accelerated, but also give opportunities to obtain clues aiming at process reconfiguration in accordance with the value-driven approach (Thomas et al., 2010; Bollen, 2016, Combi et al., 2017). The application of this method entailed the performance of the following actions in successive sequences. 1. Based on the data obtained, three therapeutic processes were modeled in the dedicated software: for ovarian carcinoma treatment if the patient initially consulted a PCP; for ovarian carcinoma treatment if the patient initially consulted a gynecologist; and for lung cancer treatment when the patient reported to a PCP. The models consisted of all events and time delays of their performance in the diagnostic subprocess. The remaining subprocesses (treatment proper and individualized post-hospital therapy) were presented in the models in the global form, as envisaged by the standard adopted. 2. Each process was then simulated in each possible variant according to minimum and maximum time that lapse from the initial patient appointment up to the moment of referring to hospital for treatment, which is equivalent to specifying a point for establishing a diagnosis. 3 . The diagnostic subprocess was improved for each model of the treatment process. 4 . The model of improved diagnosis for all three treatment processes was designed and verified. The obtained models of treatment processes and results of conducted optimization served for forming final conclusions and indicating the need for further research.

\section{RESULTS}

Each of the models encompasses all possible types of patient-healthcare system contact, organized in the form of events in accordance with the BPMN standard in swimlane diagrams (Ryan, et al., 2009; White et al., 2011; Scheuerlein et at., 2012, Combi et al., 2017 ), starting with the initial visit up to the conclusion of post-hospital individual treatment and a return to effective professional activity. The following subsections present individual models for three processes dedicated to treatment of ovarian and lung cancers.

\subsection{Model of Ovarian Cancer Treatment Process - The First Visit at a PCP Office}

The first model (Figure 1) presents possible paths of contact between an ovarian cancer patient and the healthcare system assuming that her first visit in the diagnostic subprocess took place in a PCP office. Solid lines denote a typical course of events (connection between events). Dashed lines, however, show the flow of information concerning test results. After each medical consultation with any type of doctor, alternative decisions that the doctor could make are presented. The remaining subprocesses, being a part of the treatment process but not the subject of investigation, are marked and described as follows:

1. Treatment of other diseases - both the PCP and any specialist (apart from geneticist) can diagnose diseases other than ovarian cancer and initiate a subprocess of treatment at any stage of the process.

2. Inpatient treatment - each of the doctors participating in the diagnostic process (apart from geneticist) can diagnose ovarian cancer based on 


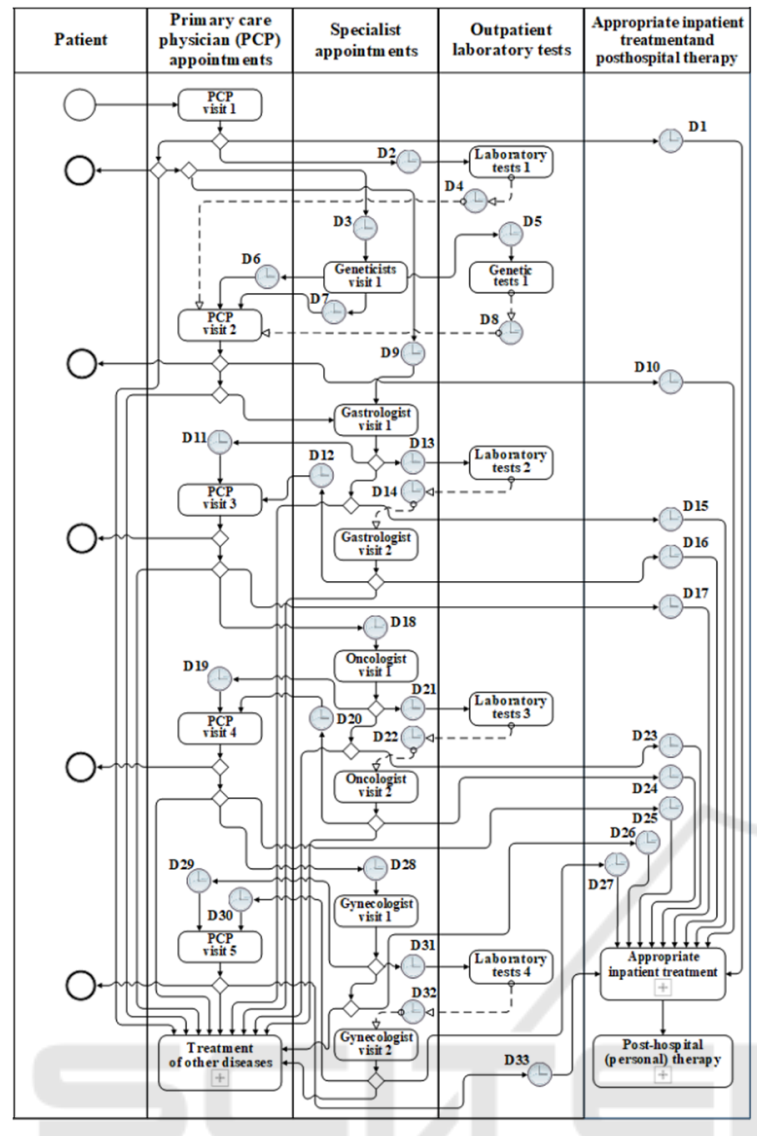

Figure 1: Model of ovarian cancer treatment process - the first visit at a PCP office.

data achieved or obtained in examinations and refer patients to hospital for proper inpatient treatment. 3. Post-hospital personal therapy - it is a subprocess of individual post-hospital treatment after the conclusion of the inpatient ovarian cancer treatment. The individual stages of the diagnostic process involve time delay, marked as D. As the model suggests, 33 maximum delays, which may negatively affect effective treatment, were identified. The model contains the maximum number of possible events in the diagnostic subprocess. The stages of specialist consultations can be repeated and their number depends on the number of specialists engaged in the diagnostic process. Events in the form of specialist appointments as consecutively referred by a PCP are therefore possible. Moreover, each specialist can repeatedly refer the patient for specialist tests proper for that doctor's specialty, according to their qualifications. This entails multiple events in terms of laboratory testing. A referral for specialist examinations entails another specialist visit upon receipt of test results. If there are no signs of a disease belonging to the field of expertise of a given specialist, the patient is again referred to a
PCP who, in turn, refers her for further examinations (in the case of issuing a referral to hospital, all examinations are conducted there). The delay in this model strictly depends on the events in the process and concern the periods of awaiting: appointments with individual physicians; performance of examinations; obtaining test results and admission to hospital. The model (Figure 1) contains a description of actions conducted by four specialists to whom the patient may be referred by a PCP: geneticist, gastrologist, oncologist and gynecologist. Minimum and maximum delay values, based on obtained data and simulations, are presented in Table 1.

Table 1: Delay in waiting for doctor appointments- ovarian cancer treatment - first visit at a PCP office.

\begin{tabular}{|l|c|c|c|}
\hline Specialist & $\begin{array}{l}\text { Wait time } \\
\text { for visit- } \\
\text { min (days) }\end{array}$ & $\begin{array}{l}\text { Wait time } \\
\text { for visit- } \\
\text { max (days) }\end{array}$ & Delay time \\
\hline PCP & 1 & 7 & $\begin{array}{c}\text { D6, D7, } \\
\text { D19, D12, } \\
\text { D29, D30 }\end{array}$ \\
\hline Gastrologist & 90 & 120 & D9 \\
\hline Geneticist & 30 & 180 & D3 \\
\hline Oncologist & 14 & 90 & D18 \\
\hline Gynecologist & 2 & 14 & D28 \\
\hline
\end{tabular}

As indicated by the data and calculations presented in Table 1, the shortest period of awaiting a visit concerns a PCP -1 day. The longest period of waiting for an appointment with a specialist among the minimum waiting periods concerns a gastrologist: 90 days. The longest possible time of awaiting consultation concerns a geneticist and may reach even 180 days. The shortest and the fastest treatment path in terms of the number of events occurs when the patient is referred to hospital during the first PCP appointment. Such situations are nearly non-existent in practice since this disease does not produce specific signs in early stages. The longest treatment path involves subsequent referrals to all specialists engaged in the treatment process. If the patient is referred by a specialist for further examinations, the second appointment with this specialist is delayed at least by the time of awaiting test results. Specialist examinations are another source of delay. This concerns both the date of their performance and awaiting results. Table 2 presents delay periods for each patient's appointment. 
Table 2: Delay in awaiting tests and results in the model of ovarian cancer diagnosis and treatment - the first visit at a PCP office.

\begin{tabular}{|l|c|c|}
\hline $\begin{array}{l}\text { Referring physician appoint- } \\
\text { ment }\end{array}$ & $\begin{array}{l}\text { Result - } \\
\text { min (days) }\end{array}$ & $\begin{array}{l}\text { Result } \\
\text { max } \\
\text { (days) }\end{array}$ \\
\hline PCP or Gynecologist & 1 & 2 \\
\hline Oncologist or Gynecologist & 7 & 14 \\
\hline PCP or Gynecologist & 14 & 28 \\
\hline PCP or Gynecologist & 1 & 2 \\
\hline $\begin{array}{l}\text { PCP or Gynecologist or On- } \\
\text { cologist }\end{array}$ & 5 & 10 \\
\hline PCP or Gynecologist & 1 & 7 \\
\hline Oncologist or Gynecologist & 30 & 120 \\
\hline Oncologist or Gynecologist & 30 & 180 \\
\hline Gastrologist or Oncologist & 30 & 180 \\
\hline Geneticist & 180 & 180 \\
\hline
\end{tabular}

The delay time contains time delay points marked as " $D$ " included in the first model (Figure 1) for duration of waiting for examinations and test results, respectively. The duration of delays ends with the duration of waiting for hospital admission. Since a referral to hospital can be issued by any physician, this delay can occur at various points during the diagnostic subprocess. They are identified as: D1, D10, D15, D16, D17, D23, D24, D25, D26, D27, D33. These delays will certainly occur only once in the diagnostic process. The time of awaiting hospital admission ranges from 1 to 14 days. Moreover, during each visit a PCP, based on test results, may decide that: 1) there are no signs of a severe disease that would require further processes in the healthcare system; 2) there is a need to initiate a different treatment subprocess; 3 ) there is a need for hospital treatment.

\subsection{Model of Ovarian Cancer Treatment Process - The First Visit at a Gynecologist Office}

Figure 2 presents a model of ovarian cancer diagnostic and therapeutic process when the patient first reports to a gynecologist. The second model (Figure 2) was drawn up based on the approach adopted in Figure 1. As the model suggests, if the patient reports first to a gynecologist, the number of specialists to whom she can be referred is lower. This also means that the number of possible laboratory examinations is lower, but the number of tests remains unchanged. In the entire diagnostic subprocess, 25 delays were noted. This number is lower by 8 compared with the previous model. Table 3 presents delay in awaiting doctor appointment in the model of ovarian cancer diagnosis and treatment when the first visit took place at a gynecologist office. The longest period of waiting for an appointment among the cases with the lowest time periods concerns a gastrologist: 90 days.

Table 3: Delay in waiting for doctor appointments- ovarian cancer treatment - the first visit at a gynecologist office.

\begin{tabular}{|l|c|c|l|}
\hline Specialist & $\begin{array}{l}\text { Wait time } \\
\text { for visit- } \\
\text { min (days) }\end{array}$ & $\begin{array}{l}\text { Wait time } \\
\text { for visit- } \\
\text { max (days) }\end{array}$ & Delay time \\
\hline Gynecologist & 2 & 14 & $\begin{array}{l}\text { D6, D7, } \\
\text { D11, D12, } \\
\text { D19, D20 }\end{array}$ \\
\hline Gastrologist & 90 & 120 & D9 \\
\hline Geneticist & 30 & 180 & D3 \\
\hline Oncologist & 14 & 90 & D18 \\
\hline
\end{tabular}

As indicated by the data and calculations presented in Table 3, the shortest period of awaiting a visit concerns a gynecologist: 2 days.

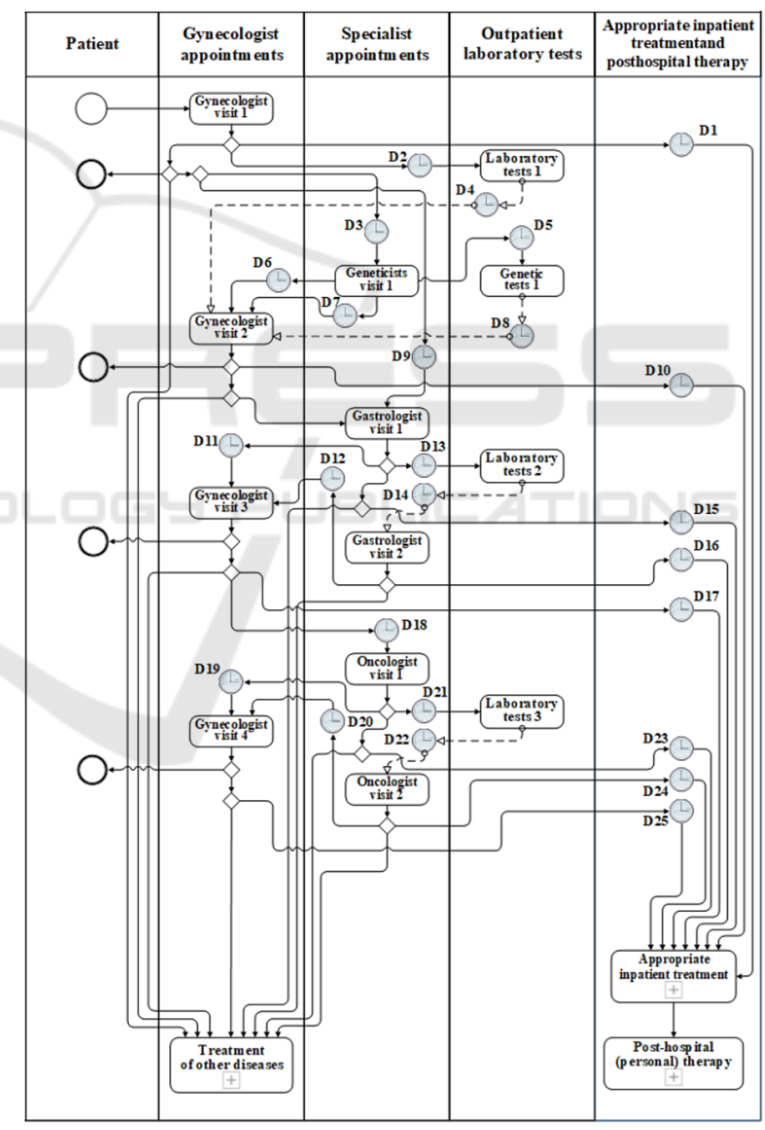

Figure 2: Model of ovarian cancer treatment process - the first visit at a gynecologist office.

The longest possible time of awaiting consultation concerns a geneticist and may reach even 180 days. Compared with the model shown in Figure 1 (the first visit - PCP), the range of delay did not change considerably, but the entire diagnostic subprocess is 
shorter by one gynecological consultation, which saves 2 to 180 days. This results from the possibility of being referred for specialist examinations as soon as during the very first visit (by a gynecologist). The remaining delays in other segments of this process still lower chances for effective treatment. The shortest path in terms of the number of events and, at the same time, the fastest treatment route takes place when a gynecologist refers the patient to hospital at the very first visit. Such situations are rare in practice because symptoms of ovarian cancer would then indicate advanced disease, the treatment of which is poorly effective. The longest treatment path involves subsequent referrals to all specialists engaged in the treatment process. As in the previous model, if the patient is referred for further examinations by a specialist, the second appointment with this specialist is delayed at least by the time of awaiting test results. Specialist examinations are another source of delay. This concerns both the date of their performance and awaiting results. Table 4 presents delay periods for each patient's appointment. The delay time contains time delay points marked as " $D$ " included in the second model (Figure 2) for duration of waiting for examinations and test results, respectively. The total delay ends with the duration of waiting for hospital admission. Since a referral to hospital can be issued by any physician, this delay can occur at various points during the diagnostic subprocess. They are marked as: D1, D10, D15, D16, D17, D23, D24, D25.

Table 4: Delay in awaiting tests and results in the model of ovarian cancer diagnosis and treatment - the first visit at a gynecologist office.

\begin{tabular}{|l|c|c|}
\hline $\begin{array}{l}\text { Referring physician appoint- } \\
\text { ment }\end{array}$ & $\begin{array}{l}\text { Result- } \\
\text { min (days) }\end{array}$ & $\begin{array}{l}\text { Result- } \\
\text { max } \\
\text { (days) }\end{array}$ \\
\hline Gynecologist & 1 & 2 \\
\hline Gynecologist or Oncologist & 7 & 14 \\
\hline Gynecologist & 14 & 28 \\
\hline Gynecologist & 1 & 2 \\
\hline Gynecologist or Oncologist & 5 & 10 \\
\hline Gynecologist & 1 & 7 \\
\hline Gynecologist or Oncologist & 30 & 120 \\
\hline Gynecologist or Oncologist & 30 & 180 \\
\hline Gastrologist or Oncologist & 30 & 180 \\
\hline Geneticist & 180 & 180 \\
\hline
\end{tabular}

These delays will certainly occur only once in the diagnostic process. As in the previous model, the time of awaiting hospital admission ranges from 1 to 14 days. Moreover, during each visit a gynecologist, based on test results, may decide that there are no signs of a severe disease that would require further processes in the healthcare system, there is a need to initiate a different treatment subprocess or that there is a need for hospital treatment.

\subsection{Model of Lung Cancer Treatment Process}

Figure 3 presents a model of lung cancer diagnostic and therapeutic process. The third model (Figure 3 ) is also based on Figure 1 (first visit at a PCP office).

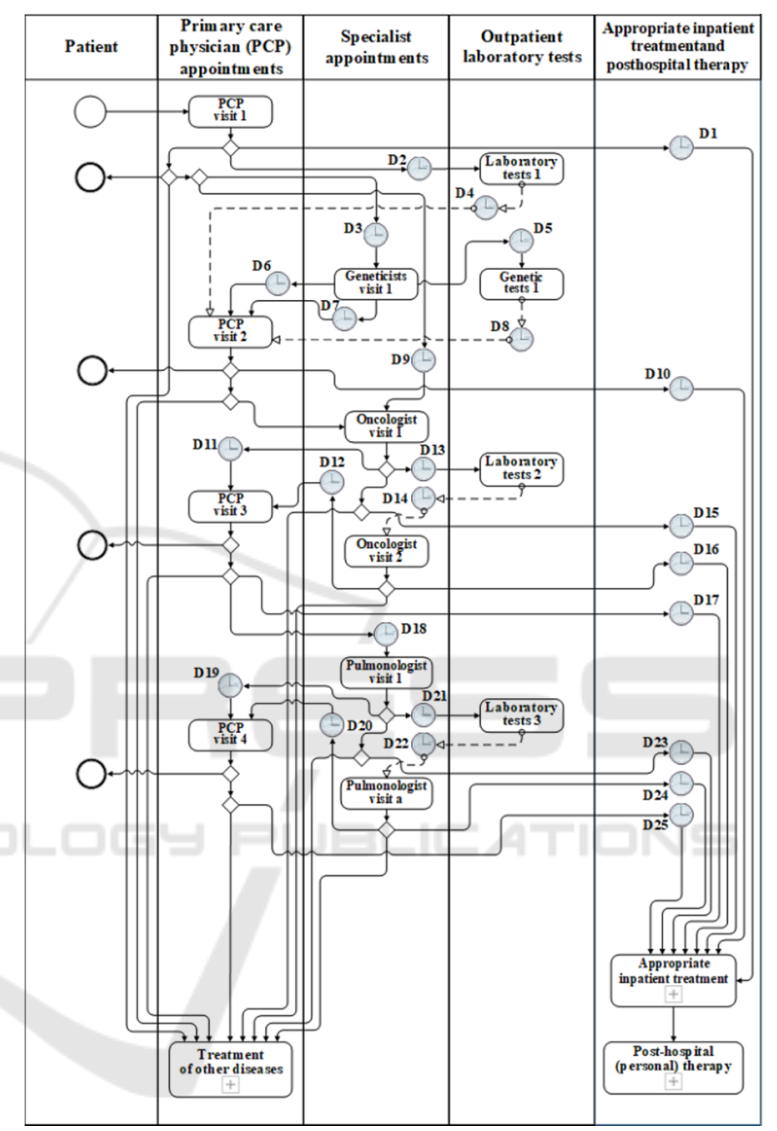

Figure 3: Model of lung cancer diagnostic and therapeutic process.

It is characterized by a lower number of specialists to whom patients may be referred. This also means that the number of possible laboratory examinations is lower, but the number of tests remains unchanged. In the entire diagnostic process, 25 delays were noted. This number is lower by 8 compared with the previous model (Figure 1). Table 5 presents delay in awaiting doctor appointment in the model of lung cancer diagnosis and treatment. As indicated by the data and calculations presented in Table 5, the shortest period of awaiting a visit concerns a PCP: 1 day. The shortest and the fastest treatment path in terms of the number 
of events occurs when the patient is referred to hospital during the first PCP appointment. Such situations are rare in practice because first symptoms of lung cancer are non-specific and require additional, sometimes numerous, examinations.

Table 5: Delay in awaiting doctor appointment in the model of lung cancer diagnosis and treatment.

\begin{tabular}{|l|c|c|l|}
\hline Specialist & $\begin{array}{l}\text { Wait time } \\
\text { for visit- } \\
\text { min (days) }\end{array}$ & $\begin{array}{l}\text { Wait time } \\
\text { for visit- } \\
\text { max (days) }\end{array}$ & Delay time \\
\hline PCP & 1 & 7 & $\begin{array}{l}\text { D6, D7, } \\
\text { D11, D12, } \\
\text { D19, D20 }\end{array}$ \\
\hline Geneticist & 30 & 180 & D3 \\
\hline Oncologist & 14 & 90 & D9 \\
\hline Pulmonologist & 14 & 120 & D18 \\
\hline
\end{tabular}

The longest period of waiting for an appointment among the events with the shortest time periods concerns a geneticist: 30 days. The longest possible time of awaiting consultation also concerns a geneticist and may reach even 180 days. The longest treatment path involves subsequent referrals to all specialists engaged in the treatment process. As in the previous models, if the patient is referred for further examinations by a specialist, the second appointment with this specialist is delayed at least by the time of awaiting test results. Specialist examinations are another source of delays. This concerns both the date of their performance and awaiting results. Table 6 presents types of examinations and delay periods that they entail.

Table 6: Delay in awaiting tests and results in the model of lung cancer diagnosis and treatment.

\begin{tabular}{|l|c|c|}
\hline $\begin{array}{l}\text { Referring physician appoint- } \\
\text { ment }\end{array}$ & $\begin{array}{l}\text { Result - } \\
\text { min } \\
\text { (days) }\end{array}$ & $\begin{array}{l}\text { Result } \\
\text { max } \\
\text { (days) }\end{array}$ \\
\hline PCP & 1 & 2 \\
\hline PCP & 14 & 28 \\
\hline PCP or Oncologist & 1 & 7 \\
\hline $\begin{array}{l}\text { PCP or Oncologist or Pul- } \\
\text { monologist }\end{array}$ & 30 & 120 \\
\hline Oncologist or Pulmonologist & 1 & 7 \\
\hline Oncologist or Pulmonologist & 31 & 62 \\
\hline Pulmonologist & 30 & 180 \\
\hline Pulmonologist & 7 & 14 \\
\hline Geneticist & 180 & 180 \\
\hline
\end{tabular}

The delay time contains time delay points marked as "D" included in the second model (Figure 3) for duration of waiting for the examination and test results, respectively. The delay ends with the duration of waiting for hospital admission. They are marked as: D1, D10, D15, D16, D17, D23, D24, D25. The time of awaiting hospital admission occurs only once and ranges from 1 to 14 days. During each visit, a PCP, based on test results, may decide that there is a need to initiate a different treatment subprocess or that there is a need for hospital treatment. The PCP can also diagnose a minor disease or prescribe certain medications, after which the patient leaves the healthcare system.

\subsection{Improved Model of Ovarian and Lung Cancer Treatment}

The model simulations yielded results presented in Table 7. It was assumed that all necessary examinations will be conducted in an optimal way, i.e. without extending the waiting period associated with their performance and receiving results. That is why the delay ranges from 1 to 180 days in each of the analyzed models. Also, delay associated with the initial PCP or gynecological visit are not taken into consideration in the simulation since, in this case, the patient makes decisions irrespective of the system in which treatment is conducted. As simulations suggest (Table 7), the longest delay is generated by repeatable loops of appointments with specialists. A question arises: Can the duration of the diagnostic process in ovarian and lung cancer be shortened significantly using the present resources of the healthcare system? The simulations indicate that two organizational changes may be performed: 1. Broadening the scope of PCP qualifications in terms of referring patients for specialist examinations, involving oncological, gynecologic and gastrological tests. 2. Organizing online medical conferences with specialists that would have access to all data that a PCP has obtained from the patient and to results of tests from within their fields of expertise. Following such a conference, a PCP can inform the patient about the results of the conference and refer them to hospital for treatment even during the second visit. These two organizational changes served for designing an improved model of ovarian and lung cancer treatment (Figure 4). First of all, the scope of PCP and gynecologist qualifications must be broadened so that patients could be referred for examinations during the first appointments. The range of tests should include the most significant tests conducted by an oncologist, gastrologist, geneticist and pulmonologist. The PCP should have the power to refer patients for gynecological examinations if symptoms suggest ovarian cancer. When all tests have been conducted in accordance with the initial diagnosis of ovarian or lung cancer it is necessary to organize an online medical conference without the need for the patient presence. Physicians that must take part in the conference 
Table 7: Simulations of ovarian and lung cancer treatment model.

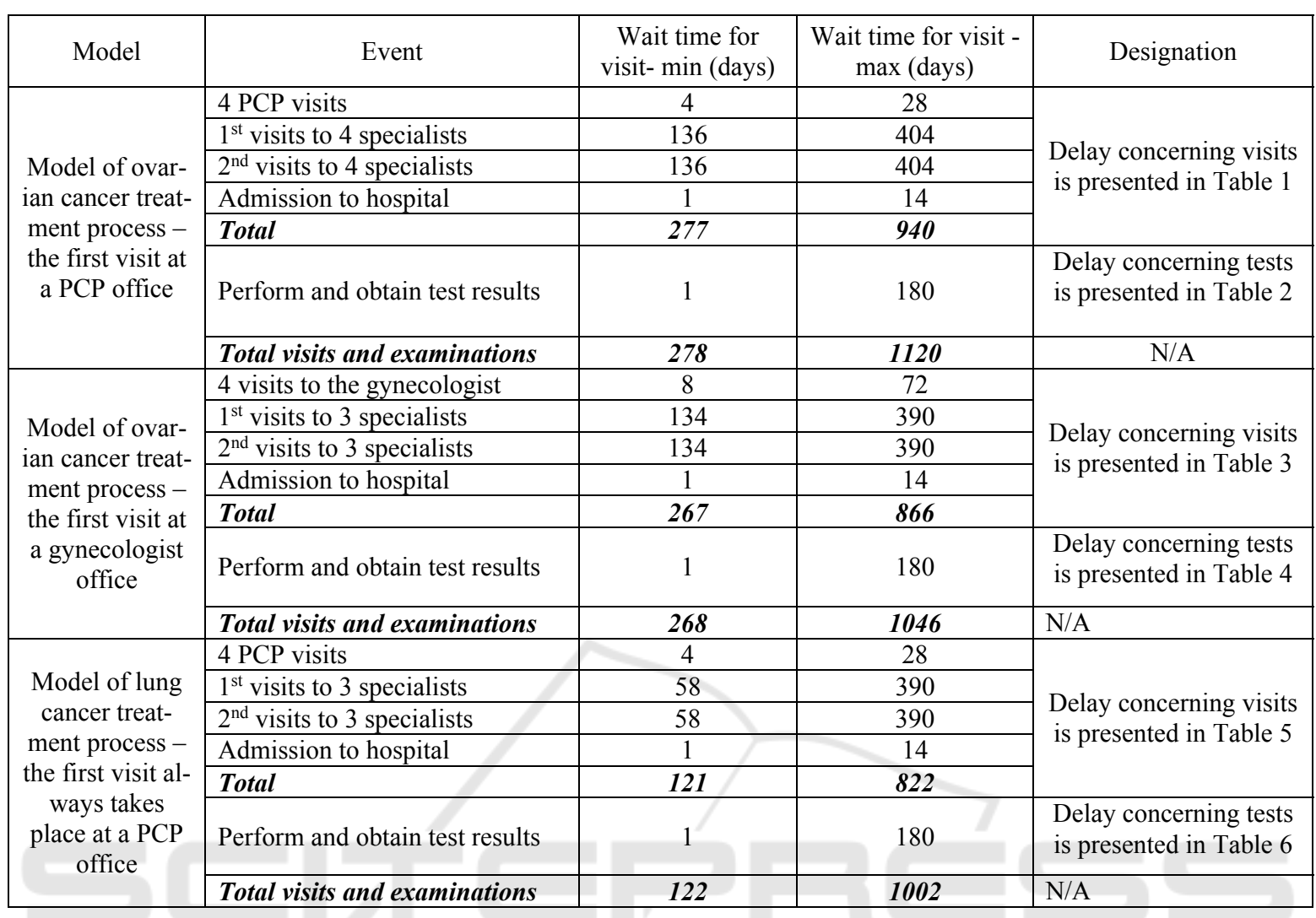

include: a PCP, oncologist and, depending on the suspected disease: gynecologist and gastrologist for ovarian cancer, or pulmonologist and thoracic surgeon for lung cancer

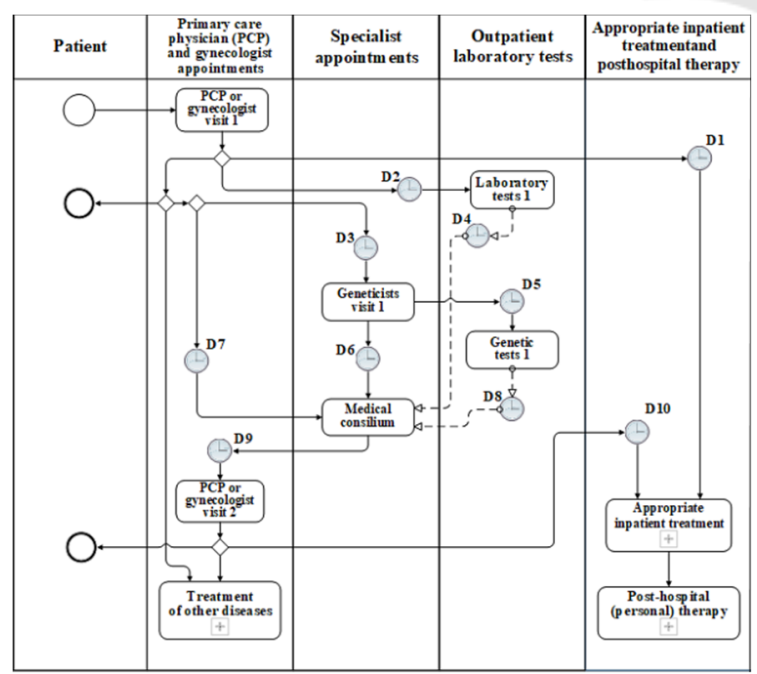

Figure 4: Improved model of ovarian and lung cancer diagnostic and therapeutic process.
Doctors taking part in such an online medical conference have access to all data collected by the PCP during the first visit and to all test results. The conference can be organized using standard and generally available tools for a video conference. Eventually, such conferences will be held regularly as the work on computerization of the health system progresses will continue with application of appropriate security measures. Doctors can make the following decisions: 1. The patient is healthy; 2 . Admission to hospital; 3 . Depending on the diagnosis, initiation of treatment for diseases other than ovarian or lung cancer. The application of the proposed solution to the treatment process of lung and ovarian cancer will reduce the time of awaiting appointments with specialists. The simulations of the optimal model of ovarian and lung cancer diagnostic and therapeutic process yielded results presented in Table 8 . For the simulation conditions to be identical to those in the previous models, it was assumed that all necessary examinations will be conducted in the optimal way, i.e. without extending the waiting period associated with their performance and receiving results. That is why the delay ranges from 1 to 180 days in each of the analyzed models. Delay associated with the initial PCP visit are 
Table 8: Results of simulations of the optimal model of ovarian and lung cancer diagnosis and treatment.

\begin{tabular}{|c|c|c|c|c|}
\hline Disease & Event & $\begin{array}{l}\text { Wait time for } \\
\text { visit-min (days) }\end{array}$ & $\begin{array}{l}\text { Wait time for visit- } \\
\max \text { (days) }\end{array}$ & Designation \\
\hline \multirow{7}{*}{$\begin{array}{l}\text { Improved model of } \\
\text { ovarian cancer treat- } \\
\text { ment process - the } \\
\text { first visit at a PCP } \\
\text { office }\end{array}$} & One PCP visit & 1 & 7 & D9 \\
\hline & One visit with a geneticist & 30 & 180 & D3 \\
\hline & Medical conference & 106 & 224 & D6, D7 \\
\hline & Admission to hospital & 1 & 14 & D1, D10 \\
\hline & Total & 138 & 425 & N/A \\
\hline & Perform and receive test results & 1 & 180 & $\begin{array}{l}\text { D2, D4, D5, } \\
\text { D8 }\end{array}$ \\
\hline & Total visits and examinations & 139 & 605 & N/A \\
\hline \multirow{7}{*}{$\begin{array}{l}\text { Improved model of } \\
\text { ovarian cancer treat- } \\
\text { ment process - the } \\
\text { first visit at a gyne- } \\
\text { cologist office }\end{array}$} & One visit to a gynecologist & 2 & 14 & D9 \\
\hline & One visit to a geneticist & 30 & 180 & D3 \\
\hline & Medical conference & 104 & 210 & D6, D7 \\
\hline & Admission to hospital & 1 & 14 & D1, D10 \\
\hline & Total & 137 & 404 & N/A \\
\hline & Perform and receive test results & 1 & 180 & $\begin{array}{l}\text { D2, D4, D5, } \\
\text { D8 }\end{array}$ \\
\hline & Total visits and examinations & 138 & 584 & $\mathrm{~N} / \mathrm{A}$ \\
\hline \multirow{7}{*}{$\begin{array}{l}\text { Improved model of } \\
\text { lung cancer treatment } \\
\text { process - the first } \\
\text { visit always takes } \\
\text { place at a PCP office }\end{array}$} & One PCA visit & 1 & 7 & D9 \\
\hline & One visit to a geneticist & 30 & 180 & D3 \\
\hline & Medical conference & 28 & 210 & D6, D7 \\
\hline & Admission to hospital & +2 & 14 & D1, D10 \\
\hline & Total & 60 & 411 & N/A \\
\hline & Perform and receive test results & 1 & 180 & $\begin{array}{l}\text { D2, D4, D5, } \\
\text { D8 }\end{array}$ \\
\hline & Total visits and examinations & 61 & 591 & $\mathrm{~N} / \mathrm{A}$ \\
\hline
\end{tabular}

not taken into consideration in the simulation since, in this case, the patient makes decisions irrespective of the system in which treatment is conducted. When conducting the simulation, all data concerning delay calculated in all models for doctor appointments, performance of examinations and obtaining test results as well as admission to hospital were used.

\section{DISCUSSION AND CONCLUSIONS}

The work presented in this paper demonstrates that organizational changes could reduce the number of delays in the diagnostic and therapeutic process of ovarian and lung cancer from 33 and 25 , respectively, to 10 in both cases with using the same number of specialists and other medical staff. Moreover, it allowed the application of one standardized diagnostic subprocess where the difference between diseases only involves different sets of specialist examinations and a different team of physicians taking part in the medical conference. Upon the introduction of changes, the improved model preserves the shortest possible diagnostic path by the possibility of issuing a referral to hospital even during the first visit. The simulation of the improved model for ovarian cancer diagnosis and treatment with the first visit at a PCP office indicates that the minimum time was reduced from 278 to 139 days, and the longest possible time of staying within the healthcare system - from 1120 to 605 days. This means reductions in the time from the first PCP visit to hospital admission by $50 \%$ and $46 \%$, respectively. In the case of the first patient visit at a gynecologist office, the minimum time was reduced from 268 to 138 days, and the maximum time - from 1046 to 584 days. This means reductions in the time from the first appointment with a gynecologist to hospital admission by $48.5 \%$ and $44.17 \%$, respectively. As for the simulation of the optimal model for lung cancer diagnosis and treatment, the minimum time was reduced from 122 to 61 days, and the longest possible time - from 1002 to 591 days. This means reductions in the time from the first PCP visit to hospital admission by $50 \%$ and $41 \%$, respectively. Considering the results reported above, it can be stated that introducing organizational changes (for now without making investments in the fixed assets and equipment), in the form of broadening the scope of PCP and gynecologist qualifications in terms of issuing referrals for specialist examinations as well as or- 
ganizing regular medical conferences online depending on the type of symptoms and initial PCP diagnosis, helps save approximately $50 \%$ of time in the subprocess of ovarian and lung cancer diagnosis. These results enable earlier decisions about referring patients for proper personalized treatment. Organizing online medical conferences without the need for the patient presence will reduce lines to specialists since in many cases, decisions will be made during the conference. Reductions in the time that would otherwise be devoted to awaiting appointments with specialists is another long-term effect of the aforementioned organizational innovation. Essential investments must be made within the Information and Communication Technologies (ICT) (rapid communication, online conferences). It is an example of how the ICT can be used in the process of diagnostic and treatment in order to reduce time for diagnostic and start personalized therapy as soon as possible. Without additional investments in specialists and medical staff, a substantial time-optimization of process brings about $50 \%$ of diagnostic time reduction.

\section{FUTURE RESEARCH}

The subsequent stage of improvement management should involve the performance of preliminary research and making a selection of facilities that perform specialist laboratory tests in order to shorten procedures and examinations, as well as reduce the time of waiting for test results (they should be available instantaneously). Another challenge for the present healthcare system is the introduction of an integrated database in which patient data and their entire medical histories could be stored. The issues presented above should constitute new research and implementation projects that need to be undertaken as soon as possible.

\section{REFERENCES}

Allweyer, T., 2008. Business Process Modeling NotationEinführung in den Standard für die Geschäftsprozessmodellierung. Books on Demand GmbH. Norderstedt.

Bollen, P., 2016. Business Process Model Semantics in BPMN. Springer-Verlag. Berlin.

Collins, L., Haines, Ch., Perkel, R., Enck, R., 2007. Lung Cancer: Diagnosis and Management. American Family Physician. 75(1), 56-63.

Combi, C., Oliboni, B., Zardini, A., Zerbato, F., 2017. A Methodological Framework for the Integrated Design of Decision-Intensive Care Pathways - an Application to the Management of COPD Patients. Journal of Healthcare Informatics Research. 12(1), 157-217.

Didkowska, J, Wojciechowska, U., 2015. Nowotwory złośliwe w Polsce w 2013 roku. Zakład Epidemiologii KRN. Warszawa.

Evans, J., Ziebland, S., McPherson, A., 2007. Minimizing delays in ovarian cancer diagnosis: an expansion of Andersen's model of "total patient delay". Family Practice. 24(2), 48-55.

Grosskopf, A, Decker, G, Weske, M., 2009. The Process: Business Process Modeling using BPMN. Meghan Kiffer Press. New York.

Havrileskya, L., Broadwatere, G., Davisa, D., Noltea, K., Barnetta, J., Myersb, E., Kulasingamb, S., 2009. Determination of quality of life-related utilities for health states relevant to ovarian cancer diagnosis and treatment. Gynecologic Oncology. 113(2), 216-220.

Kunze, M, Weske, M., 2016. Behavioural Models: From modelling finite automata to analyzing business processes. Springer-Verlag. Berlin.

Ouyang, C., Dumas, M., Ter Hofstede, H., Van Der Aalst, M., 2008. Pattern-based translation of BPMN process models to BPEL web services. International Journal of Web Services Research. 5: 42-61.

Rivera, M., Mehta, A., Wahidi, M., 2013. Establishing the Diagnosis of Lung Cancer: Diagnosis and Management of Lung Cancer. American College of Chest Physicians Evidence-Based Clinical Practice Guidelines. 143(5), 10-40.

Ryan K. L., Lee, S., Lee, W., 2009. Business process management (BPM) standards: a survey. Business Process Management Journal. 15(5), 744-791.

Scheuerlein, H., Rauchfuss, F., Dittmar, Y., Molle, R., Lehmann, T., Pienkos, N., Settmacher, U., 2012. New methods for clinical pathways - Business Process Modeling Notation (BPMN) and Tangible Business Process Modeling BPM. Langenbeck's Archives of Surgery. 397(5), 755-761.

Steward, R. W., Wild, C. P., 2015. WHO, World Cancer Report 2014. International Agency for Research on Cancer Publishers. London.

The EUROCARE-5 Working Group-5., 2014. Cancer survival in Europe 1999-2007 by country and age: results of EUROCARE-5 - a population-based study. The Lancet Oncology. 15(1), 23-34.

Thomas, O., Vom Brocke, J., 2010. A value-driven approach to the design of service-oriented information systems - making use of conceptual models. Information Systems and e-Business Management. 8(1), $67-$ 97.

White, SA, Bock, C., 2011. BPMN 2.0 Handbook Second Edition: Methods, Concepts, Case Studies and Standards in Business Process Management Notation. Future Strategies Inc. New York. 